\title{
A NEW PROOF OF BERNSTEIN'S INEQUALITY FOR LEGENDRE POLYNOMIALS
}

\author{
V. MARIĆ AND M. TOMIĆ
}

ABSTRACT. A proof of the classical Bernstein's inequality for Legendre polynomials via the Stieltjes representation for the latter is presented.

The inequality states that

$$
(\sin \theta)^{1 / 2}\left|P_{n}(\cos \theta)\right|<(2 / \pi)^{1 / 2} n^{-1 / 2}, \quad 0 \leq \theta \leq \pi, n=1,2, \cdots .
$$

The constant multiplying $n^{-1 / 2}$ was gradually improved from $4(2 / \pi)^{1 / 2}$ by Stieltjes, Gronwall and Fejér to the best possible value $(2 / \pi)^{1 / 2}$ obtained by S. Bernstein (see [1]).

In contrast to the original one, which makes use of the relevant differential equation [1, Theorem 7.3.3], our proof starts with the Stieltjes representation

$$
P_{n}(\cos \theta)=\frac{2}{\pi} \mathcal{J}_{m}\left\{e^{i(n+1) \theta} \int_{0}^{1} t^{n}(1-t)^{-1 / 2}\left(1-t e^{2 i \theta}\right)^{-1 / 2} d t\right\}
$$

$0<\theta<\pi$, and runs as follows:

Majorizing in (2) by absolute values, and using the inequality

$$
\left(1-2 t \cos 2 \theta+t^{2}\right)^{-1 / 4} \leq(2 t \sin \theta)^{-1 / 2}, \quad 0<\theta<\pi, 0<t \leq 1,
$$

which is easily verified by direct computation, one obtains

$$
\left|P_{n}(\cos \theta)\right| \leq 2^{1 / 2}(\sin \theta)^{-1 / 2} T_{n}, \quad 0<\theta<\pi,
$$

where

$$
T_{n}=\pi^{-1} \int_{0}^{1} t^{n-1 / 2}(1-t)^{-1 / 2} d t=(2 n) !(n !)-22^{-2 n}
$$

Now the sequence $(2 n)^{1 / 2} T_{n}$ increases and, by Stirling's formula, tends to $(2 / \pi)^{1 / 2}$; hence $T_{n}<(\pi n)^{-1 / 2}$ for all $n$, which, together with (4) proves (1).

Received by the editors February 13, 1974. $26 A 86$.

AMS (MOS) subject classifications (1970). Primary 33A45, 33A65; Secondary

Key words and phrases. Bernstein's inequality, Legendre polynomials, Stieltjes representation, Stirling's formula. 


\section{REFERENCE}

1. G. Szego, Orthogonal polynomials, Amer. Math. Soc. Colloq. Publ., vol. 23, rev. ed., Amer. Math. Soc., Providence, R. I., 1959. MR 21 \#5029.

INSTITUTE OF PHYSICS AND MATHEMATICS, UNIVERSITY OF NOVI SAD, NOVI SAD, YUGOSLAVIA

FACULTY OF MINING ENGINEERING, UNIVERSITY OF BELGRADE, BELGRADE, YUGOSLAVIA 